\title{
Improving Ethical Decision Making Through the Application of Psychological Knowledge
}

\author{
Avi Kay \\ Jerusalem College of Technology
}

\begin{abstract}
The abstract is to be in fully-justified italicized text, at the top of the left-hand column as it is here, below the author information. Use the word "Abstract" as the title, in 12-point Times, boldface type, centered relative to the column, initially capitalized. The abstract is to be in 10-point, singlespaced type, and up to 150 words in length. Leave two blank lines after the abstract, then begin the main text.
\end{abstract}

"One of the greatest reasons why so few people understand themselves is that most writers are always telling man what they should be, and hardly ever trouble their heads with telling them what they really are.”

- Bernard Mandeville “Fable of the Bees” (1714)

\section{Introduction}

Clearly, something has gone wrong. Multiple and widely publicized - moral failings of business organizations have generated long, and often repetitious, discussion concerning the way and reason business is practiced as it is - focusing on the moral performance of business professionals. [1], [2]. Much of this discussion has focused on the role of formal, professional business education on the subsequent conduct of business and business people. [3], [4], [5], [6].

The acknowledgment of the need to increase ethical training is, of course, to be welcomed. However, it will be suggested here that - as currently conceived - the efforts directed at business ethics' education are doomed to fail. The reason that these efforts will ultimately "come up short" is an inherent failure in the curriculum evident in the fact that when addressing ethical decision making, business ethics education currently focuses almost exclusively on the teaching of philosophical approaches and models of ethical decision making, while virtually ignoring the possible contributions of the psychological literature regarding the matter. Consequently, current business ethics education over-emphasizes what business-people should do when confronting moral challenges at the workplace at the expense of what they are likely to do.

\begin{abstract}
Alluding to the above, in a recent journal volume dedicated to education in the realm of ethics and social responsibility, Giacalone and Thompson [7] noted that it is clear "that concern for business ethics and social responsibility must go beyond traditional philosophical foci toward more positive and behaviorally focused approaches" (p. 262). Moberg pointed out that the above often has a serious impact on the lives of many businesspeople as as the disconfirmation of the role of ethics in business organizations is, for many, much more than a professional crisis - it is a personal crisis. This crisis may be aggravated by the fact that individuals may be less than adequately equipped with information regarding how people, groups and organizations "really behave." [8]

Related to the above, Giacalone and Thompson further suggest that:

"the inoculations to immoral behavior that we provide students, often through

the direction of philosophical strategies and notions of social responsibility, are inadequate......Undoubtedly, it is this stream of bad news that leaves us asking how teaching ethics and social responsibility might mitigate the problem...."[7], pp. 2005.
\end{abstract}

How indeed? It is believed that business ethics education must be an "enabling process" aimed at equipping students with the necessary knowledge and tools to successfully confront the business realities in which they are to operate. It is believed that the wider inclusion of psychological knowledge in business ethics education can be that "enabling process."

\section{The Current State of Business Ethics Education}

As noted, ethics education has increasingly become a more central focus of business education i.e. [1], [2], [7]. This focus is reflected both in the decisions of such bodies as the International Association for Management Education (AACSB) to promoted ethics' education as well as in the exponential growth in research and writing in the area of business ethics. Indeed, a perusal of the holdings of the United States Library of Congress reveals that over $80 \%$ of the materials listed under 
"business ethics" have been written over the last decade. While some [9] have exhibited a degree of cynicism with regard to what is termed as a "frenzy of activities in business schools around the world" (p. 75) related to business ethics; even they acknowledged the central role played by business education in the crafting of the business environment which may subsequently prevail. Thus, in light of the potential impact of ethics' education on the individual, organization and society, it is important to examine the precise nature of that education.

One way to assess the nature and content of ethics' education is via an examination of syllabi of pertinent courses. A perusal of syllabi of both top rated and "middling" undergraduate and graduate programs in business, as rated by the journal, Business Week, confirms the fact that scant attention is paid to psychological factors that might impinge on the ethical reality of the business organization [10]. Rather, the focus of these syllabi was on: (1) conveying information regarding the development of contemporary economic theory and systems, (2) explication of systems and philosophical theories related to moral decision making and (3) the presentation of cases related to various functions of the business organization (finance, human resources, marketing etc.).

Another way in which to ascertain what issues come to play in business ethics' education is to examine materials commonly used in those courses. An examination of the most popular texts for courses in business ethics in the United Kingdom revealed that there was a uniform disregard of the psychological dynamics of business ethics. While, no official ranking of business ethics texts by popularity for the United States seems to exist, a perusal of the texts frequently cited in syllabi also revealed an almost complete absence of psychological material. When there is a reference to psychology, it is invariably confined to a rather cursory presentation of Kohlberg's [11] theory of moral development. A notable exception to the above is Trevino and Nelson's Managing Ethics in Business Organizations [12] which makes note of both some personality and cognitive factors which may impact ethical decision making.

\section{The Possible Contribution of the Psychological Literature to Ethical Decision Making}

It will be suggested here that there are, at least, three streams of psychology literature that can contribute to the optimal training of business professionals: the developmental psychology literature, the personality psychology literature and the social psychology literature. Each of these streams - and its potential contribution to business ethics' education - will be briefly presented.

\subsection{Developmental Psychology and Ethical Reasoning}

Developmental psychology addresses changes in behavioral, perceptual, and cognitive capacities as a function of age and experience. In terms of business ethics, the relevant literature includes moral development and theories addressing the various stages of life that one may traverse during the lifespan.

Moral development is concerned with the mechanism by which individuals acquire a calculus by which they determine right from wrong. The two names most widely associated with this approach are Jean Piaget and Lawrence Kohlberg. Expanding on the work of the former, Kohlberg [11] forwarded a model of moral development which is the most widely known and cited today (as noted it also accounts for most of the "psychological thinking" included in business ethics' texts).

That model proposed that from childhood until early adulthood, individuals advance from less to more sophisticated moral reasoning. Kohlberg suggested that six stages of moral reasoning can be distinguished which reflect three, more general, stages of moral thinking termed: preconventional, conventional and postconventional thinking. These stages are universal, sequential and predictive of how one may perceive an ethical dilemma.

Preconventional thinkers view rules as external to themselves and choose to abide by such rules to the degree that they allow them to avoid punishment (stage 1) or advance their own interests (stage 2). Those in the conventional level find some value in rules as mechanisms to create and maintain order and will follow them to the degree that they assist them to meet the expectations of others (stage 3) or contribute to social order (stage 4). Postconventional thinkers see rules as part of a social contract and will operate according to those rules to the degree that they protect the rights of others (stage 5) or advance the realization of some universal principle which can serve as a prism by which to view accepted social practices, norms and laws.

While, it is not difficult to make a rough assessment of an individuals' stage of moral development through the use of the "classic" Kohlbergian ethical dilemma, Lind offers a more robust and clear-cut method by which to measure moral development [13]. Lind's "Moral Judgment Test" checks the degree to which respondents subscribe to a variety of explanations for either supporting or opposing moral decisions. While Lind notes that the tool is not intended as a basis to make individual level decisions, it does allow for both the comparison of individuals regarding moral reasoning and the examination $f$ intra-personal changes 
regarding the matter. As such, it strengthens and extends the premise of Kohlberg's work regarding moral development into a more empirically salient construct with potential use to compare individuals and measure the efficacy of ethics training programs.

An additional element of research in developmental psychology that can contribute to a more fully-integrated understanding of the moral behavior of individuals is related to the stages individuals traverse during the life-course. Within the context of this work the focus will be on the most influential theory of adult development: that of Erik Erikson. [14]

Erikson suggested that individuals pass through eight stages during the life-course. Each of these stages has a particular challenge or goal that must be met for healthy development. According to Erikson, adults spend the lion's-share of their life in a stage of development during which they may arrive at two possible outcomes; either "stagnation" or "generativity." "Stagnation" is an outcome in which one becomes focused on one's own needs and interests. "Generativity" comes about when one exhibits a "concern with creating and guiding the next generation" (p. 263). The importance of the "other" in generativity, along with its long-term focus makes it a likely breeding ground for ethical behavior.

Indeed, in the incisive analysis of American society, The Good Society [15], the authors suggest that it would behoove American society to embrace generativity as a means to "anchor our economic and political institutions firmly in the moral discourse of citizens concerned about the common good and the long run” (p. 279). McAdams and de St. Aubin and others have consistently found that individuals who scored high on generativity scales exhibit more helping behavior, concern for others and volunteerism [16]. Keyes and Ryff [17] found that generative individuals were more likely to exhibit more concern about the welfare and well-being of others and a general obligation to society. Similarly, Horwitz [18] found a link between generativity and social activism. In one of the few journal articles which brings psychology to bear on ethics, Giacalone, Paul and Jurkiewicz [19] show that generativity is positively linked with sensitivity to corporate social performance. ${ }^{1}$

Thus, it would seem that it is at least conceivable - if not likely - that there may exist a positive correlation between generativity and the desire to behave in a manner reflective of moral

\footnotetext{
${ }^{1}$ While, it is important to note that Giacolone et.al. addressed the feelings of consumers toward corporate social responsibility, it seems likely that the generativity construct would lead to similar feelings among employees, too.
}

precepts. ${ }^{2}$ Here too then, generativity might allow for the prediction of ethical behavior at the workplace and/or the willingness to consider ethical arguments in making business decisions in a manner forwarded by Rest [20].

Classroom Activities related to Developmental Psychology and Ethical Reasoning

In order to further explicate the potential role of developmental psychology in advancing ethical reasoning in business setting, it is suggested to allow students a number of opportunities to experience decision making settings. That is to say, business ethics education should make expansive use of case studies in which the students must determine what is their own "best" answer for various possible ethical dilemmas in business.

Drawing on the Kohlbergian tradition, it seems important for students to be focused on the reasons they choose the solution they choose to an ethical dilemma. Specifically, the Kohlbergian tradition would also lead them to determine who's interests they take into account when trying to reach their own best solution. As such, it serves as a way to focus students on the issues of "stakeholders" - those individuals whose interests are taken into account when making an ethical decision. Lind and others [13] have suggested that practicing moral decision making increases the proclivity for individual to "grow" in that area.

In addition to the above, Lind's [13] measure of moral justice can also be integrated into the coursework in order to try to assess changes in the level and nature of moral justice reasoning as a result to the exposure to classes in business ethics (or the business curriculum, in general). An examination of the impact of the business education received by students on moral reasoning seems to have tremendous importance for the creation of more effective business ethics' training.

\subsection{Personality Psychology and Ethical Reasoning}

Personality psychology aims to categorize and understand the causes of individual differences in patterns of behavior. In terms of the teaching of business ethics two central, germane areas are the

\footnotetext{
${ }^{2}$ Of course, an argument may be made that one person's "moral precept" is another person's "moral bankruptcy." However, it seems clear that there would be a predisposition to live "an observed life" for those with high levels of generativity. This would seemingly contribute to the type of introspection regarding one's own values and motives as well greater attention to the needs of others. Thus, individuals high on generativity might be both more likely to act according to their moral compass and/or be more receptive of moral training and arguments.
} 
literature related to overall personality type and locus of control.

Currently, the most accepted and widely used means of personality assessment is the "Big Five" approach. Building on previous research in personality psychology, Costa and McRae [21] suggested that personality can be best understood through the classification of individuals on five central traits: conscientiousness, extroversion, agreeableness, neuroticism and openness to new experience. Numerous international studies have shown the robustness of both the theoretical underpinnings of this approach and a variety of measures used to assess personality according to it [22].

Barrick and Mount have demonstrated the importance of the Big Five in work settings; with conscientiousness seen as a particularly potent predictor of a variety of positive workplace outcomes such as commitment, motivation, persistence and quality control [23]. Moberg correctly identified the potential contribution of the "Big Five" to the explication of behavior in the realm of ethics, but offered no clear road-map by which to pursue the matter [8]. Based upon existing research, it seems likely that individuals high on the trait of "conscientiousness" and/or "agreeableness" would be predisposed to more easily perceive and consider ethical arguments. Thus, all other things held even, the variety of statistically robust measures currently in use regarding the "Big Five" could help managers understand the possible "ethical potential" of prospective and current employees. Equipped with that knowledge they could both better formulate selection processes and ethical training in the organization.

Another possible contribution to understanding ethical behavior at the workplace is related to work done by Julian Rotter who suggested that it was possible to distinguish individuals based upon their expectations in respect to where control lay with regard to events in their life. Subsequent research has suggested that the individual's sense of "locus of control" is associated with a variety of personality features such as: individual initiative, susceptibility to outside influence and stress [24], [25]. Not surprisingly, a variety of studies have shown that locus of control also impacts on ethical reasoning; with "internals" being more likely to display independence of thought with regard to ethical dilemmas. An understanding of this dynamic can be, potentially, of tremendous importance to both the individual worker and managers [26], [27].

Classroom Activities related to Personality Psychology and Ethical Reasoning

Classroom activities related personality psychology and ethical reasoning can focus both on an examination of the means by which personality psychology can be brought to bear on the selection and training or individuals so as to advance ethical behavior in the organization. Student scan be called upon to examine the on-going organizational issues which might likely interface with the ethical dilemmas at the workplace. In addition to the above, students can be called upon to examine archival materials in which business leaders (both those involved in ethical lapses and those not connected to such) speak about their own beliefs, values and goals..

\subsection{Social Psychology and Ethical Reasoning}

Social Psychology studies the social nature of the individual or how the actual, imagined, or implied presence of others influences the thoughts, feelings, and behaviors of the individual. A wide variety of research undertaken within the realm of social psychology has pertinence for business ethics. Within the purview of this paper four areas of social psychological research will be addressed: conformity, obedience, diffusion of responsibility and the power of roles in the shaping of individual behavior.

\section{Conformity}

Conformity is one of the expressions of an area of study called social influence and refers to the gravitation of the individual toward the norms and expectations of groups in which they operate on the basis of explicit or implicit social pressure, Asch offered a cogent example of how conformity pressures play a role even in situations in which the individuals act in groups with no previous experience or contact [28].

In his classic experiment, people were asked to make judgments regarding the length of sets of lines with which they were presented. Though, the situation was bereft of social pressures typically to be expected in an established group situation, and the task at hand was simple and unambiguous; $38 \%$ of the answers given reflected conformity to the incorrect answer. In fact, nearly two-thirds of the subjects gave at least one incorrect response.

Regardless as to whether the conformity is reflective of "real" changes in an individual's judgment or simply an expression of pressure not to deviate from the norm [29]; it can be a powerful mechanism in the dynamics of individual and group decision making. This impact is clearly further augmented by situations in which groups have established both previous norms or beliefs and behaviors and, perhaps, even social relationships. This latter scenario seems an accurate assessment of most frameworks in which business decisions are taken.

Obedience

In what has become one of the most cited social science study of all times, Milgram [30] presented a study regarding the dynamics of obedience which is 
both intriguing and disquieting with regard to the nature on the individual. In that study, a "teacher" (the actual subject of the experiment) is instructed to help a "learner" (who, like the "experimenter" was played by an actor) learn a series of word associations via the use of steadily increasing electric shocks. The experiment illustrated the willingness of "average people" (a wide cross-section of the population) to do an "abnormal thing" (to administer significant electric shocks to others as part of an experiment on learning) ${ }^{3}$ for "no good reason" (other than that they were requested to do so by an individual responsible for an experiment in which they volunteered to participated).

Milgram noted that, before the experiment took place he and others (students, mental health professionals) estimated that less than $10 \%$ of the subjects would be willing to administer the more potent shocks in the experimental situation. In fact, over two-thirds actually did so. In one of the series of variations on the original experiment, Milgram created a situation which bears a particular semblance to one type of organizational reality in which many find themselves; a situation in which one individual requested that another administer the shock. ${ }^{4}$ Under those conditions $93 \%$ (!) of the subjects requested their partner to administer the maximum shock at the 450 volt level. Subsequent research supported Milgram's findings and conclusions in both general settings [31]; and specifically in organizational settings [32]. Diffusion of Responsibility

Kitty Genovese died famously and tragically alone while 38 of her neighbors looked-on. With that, the details of her death are now known to millions throughout the world as a result of the research initiated to better understand the human

\footnotetext{
33 The "teacher" would press a lever on a machine on which the voltage level (at 15 volt intervals) of the shocks was indicated. The highest level of shock was 450 volt and it appeared along with the text "DangerExtreme shock). Of course, as is widely known, the recipient of the punishment was a confederate of the experimenter and no electric shocks were actually administered. With that, without exception those who had participated in the experiment indicated that they were certain that they had, indeed, administered electric shocks. The subsequent emotional discomfort of many of those individuals was one of the catalysts toward much more strict human subject guidelines for experiments.

4 This dynamic can be seen to resemble a variety of organizational settings in which individuals may be asked by other to undertake actions which may easily lead to ethical problems such as to meet unreasonable market quotas, cut corners on product design, present financial information in a questionable way etc.
}

dynamics that allowed for it to occur [33], [34]. In those and subsequent pieces of research, the notion and nature of "diffusion of responsibility" have been mapped out.

"Diffusion of responsibility" refers to a dynamic that can occur when individuals alter their behavior in a group situation in which responsibility for action is not explicitly assigned. In one experiment, John Darley and Bibb Latane [33] tested what would happen when individuals are presented with a situation in which they have reason to believe that a fellow research subject has broken their ankle. Research showed that, while $70 \%$ of those individuals who experienced the situation alone as a naïve subject responded to the cry for help; that number dropped to only $40 \%$ when three naïve subjects were presented with the situation and to $7 \%$ when the naïve subject was exposed to the situation in the company of two confederates who were instructed to ignore the cries of help.

Lest one think that this phenomenon only occurs when someone else is to benefit from one's action; Latane and Darley [34] created a situation in which the research subjects themselves were exposed to potential danger via smoke pumped into the research area indicative, perhaps of a fire. Here too, the presence of others significantly altered individual behavior. While $75 \%$ of those alone acted as a result of the smoke when alone; this number dropped to only $38 \%$ when three naïve subjects were together and $10 \%$ when they were paired with confederates instructed to remain passive.

Both the work of Darley and Latane and subsequent research suggest that in order for individuals to assume responsibility and intervene in a situation, a number of conditions must exist [35]. First, the individuals must perceive the situation as warranting intervention. Next, the individual must view himself or herself as being the right person (on the basis of individual skills, knowledge, power, prestige etc.) to intervene. Finally, the individuals must view intervention as leading to desirable outcomes. Clearly, variations in the individual and/or organizational reality can easily be seen to potentially have a significant impact on how this dynamic may play out in reality and influence ethical decision making in the organization setting. Power of Roles in Shaping Individual Behavior

The last element of social psychology whose impact on ethical decision making that will be examined relates to how roles may shape one's ethical behavior. The groundbreaking experiment in this area was what has become known as "The Stanford Prison Experiment” that was led by Philip Zimbardo [36, [37]. Zimbardo and his colleagues recruited college students who were randomly assigned either the role of prisoner or guard in a mock prison created at Stanford University for the purpose of this experiment. The experiment aimed to 
examine the relationship between individual personality factors and the likelihood to engage in abusive behavior.

"Prisoners" were given no special instructions to prepare for their role, but Zimbardo and his colleagues created a series of conditions intended to create a sense of disorientation and deindividualization among them. The "guards" for their part were given uniforms and dark glasses so as to create a situation in which the "prisoners" could not make eye contact with them.

The experiment was planned to last two weeks. However, already on the second day a "mini-riot" took place against the "guards" who engaged in increasingly strict and - eventually - abusive behavior. The situation deteriorated quickly as both "prisoners" and "guards" seemed to fully assume the roles and expected behaviors of the group to which they were assigned. Five of the "prisoners" were released due to emotional distress and the many of the "guards" had to be restrained so as to not overstep their roles. On day six - to the chagrin of many of the "guards" - the experiment was halted.

Zimbardo and his colleagues pointed to the tremendous impact that the roles that the students were assigned on their subsequent behavior. Indeed, individual personality profiles seemed to have no relationship with the actual behavior of the students. The experiment points to the impact of situational factors on behavior; as well as the strength that role "requirements" ("real” or "assumed") have on individual behavior.

While, some have called into question the generalizability of the results reported by Zimbardo and his colleagues [38], the results have been replicated elsewhere. Indeed, they seem to fit in well with both situations of general abusive behavior generated by the conditions created in military settings (the abuse of prisoners in Abu Ghraib in Iraq) and business settings (the abuse of consumers with regard to product markets such as alcohol, tobacco and gambling). At any rate, it seems clear that situational factors are key to the understanding of how good people make bad decisions and even actively engage in evil [39].

Classroom Activities related to Social Psychology and Ethical Reasoning

As seen, the potential impact of social psychology on ethical reasoning is tremendous both with regard to its expansiveness and potential influence. Within the classroom, students can be asked to examine their own "social" realities and speak about times in which the social forces described above may have influenced their own behavior and/or that of others.

In addition, using both the knowledge gained from the coursework and their own examination of their personal experiences, students can be asked to consider how one might create social situations in which the social forces which can adversely affect ethical reasoning may be controlled and diminished.

\section{Conclusion}

The clearly stated purpose of this piece was to illustrate the need to include an examination of psychological phenomenon in the teaching and training of business ethics. To that end, a variety of studies indicative of some of what psychology has to offer in the way of the advancement and enhancement of our understanding of how business ethics may play out in reality were presented.

The underlying premise of the work is that the only opportunity that tomorrow's business leaders have to systematically examine the potential ethical aspects of their professional lives is during their formal education. As noted at the outset of this work, clearly something has gone wrong. Thus, if society values a marketplace in which economic actors are able to truly also consider possible ethical implications of their own actions and the business reality in which they operate - then business ethics' education must change. It must move away from a theoretical, philosophical approach to business ethics to a more realistic and practical approach that fully acknowledges individual and organizational psychological dynamics.

Indeed, it should seem clear that in order to more adequately prepare business students and leaders for the reality of the business world it is important for them to gain insight into the reality of how they and others are likely to perceive, understand and act with regard to business decisions with potential ethical dimension.

\section{References}

[1] Etzioni, A. "When it Comes to Ethics. B-schools Get an F". The Washington Post, August 4, 2002, pp. B04.

[2] Ghoshal, S. "Bad Management Theories are Destroying Good Management Practices. Academy of Management Learning \& Education, 4(); 2005, pp. 75-91.

[3] Anand, V.; Ashforth, B. and Joshi, M. "Business as Usual: The Acceptance and Perception of Corruption in Organizations." Academy of Management Executive, 19(4); 2004, pp. 9-23.

[4] Giacalone, R. and Thompson, K. "Business Ethics and Social Responsibility Education: Shifting the Worldview. The Academy of Management Learning and Education, 5, 2006, pp. 266-277.

[5] Mintzberg, H. Managers not MBAs. San Francisco, CA: Berrett-Koehler Publishers: 2004.

[6] Pfeffer, J. and Fong, C. "The End of Business Schools? Less Success than Meets the Eye." Academy of Management Learning \& Education, 2002, pp. 78-96. 
[7 Giacalone, R. and Thompson, K. "From the Guest CoEditors: Special Issue on Ethics and Social Responsibility." The Academy of Management Learning and Education, 5: 2006, pp. 261-265.

[8] Moberg, D. "The Big Five and Organizational Virtue." Business Ethics Quarterly 9,(2), 1999, pp. 245-272.

[9] Ghoshal, S.(2005). "Bad Management Theories are Destroying Good Management Practices.” Academy of Management Learning \& Education, 4): pp. 7591.

[10] "Business Weeks' Top Rated B-Schools." Available on the internet on November 20, 2006 at www.businessweek.com/bschools.

[11] Kohlberg, L. "Moral Stages and Moralization: The Cognitive Developmental Approach” In T. Lockona (Ed.) Moral Development and Behavior. New York: Holt, Rinehart and Winston, 1976, pp. 31-69.

[12] Trevino, L. and Nelson, K. Managing Ethics in Business Organizations. New York: John Wiley \& Sons, 2010.

[13] Lind, G. \& Wakenhut, R. “Testing for moral judgment competence”. In G. Lind, H.A. Hartmann \& R. Wakenhut, Eds., Moral Development and the Social Environment. Chicago: Precedent Publishing, 1985, pp. 79-105.

[14] Erikson, E. Childhood and Society. New York: Norton, 1950.

[15] Bellah, R.; Madsen, R.; Sullivan, W.; Swidler, A. and Tipton, S. Habits of the Heart: Individualism and Commitment in American Life. Berkeley: University of California Press, 1985.

[16] McAdams, D. and de St. Aubin, E. Generativity and Adult Development: How and Why We Care About the Next Generation. Washington, D.C.: American Psychological Association, 1998.

[17] Keyes, C. and Ryff, C. (1998). "Generativity in Adult Lives: Social Structural Contours and Quality of Life Consequences.” In D. McAdams and E. de St. Aubin (Eds.). Generativity and Adult Developmental: How and Why We Care for the Next Generation. Washington: American Psychological Association Press, pp. 227-264.

[18] Horwitz, W. "Developmental Origins of Environmental Ethics: The Life Experiences of Activists." Ethics and Behavior, 6(1), 1996, pp. 29-53.

[19] Giacolone, R.; Paul, K. and Jurkiewicz, C. (2005).“A Preliminary Investigation into the Role of Positive Psychology in Consumer Sensitivity to Corporate Social Performance.” Journal of Business Ethics, 58 (4), 2005, 295-305.

[20] Rest, J. Moral Development: Advances in Research. Westport, CT: Praeger, 1986.
[21] Costa, P.T., Jr. \& McCrae, R.R. The NEO Personality Inventory manual. Odessa, FL: Psychological Assessment Resources, 1985.

[22] McAdams, D. The Person: A New Introduction to Personality Psychology. New York: John Wiley \& Sons, 2005.

[23] Barrick, M. and Mount, M. "The Big Five Personality Dimensions and Job Performance: A Meta-analysis." Personnel Psychology, 44, 1991, pp.1-26.

[24] Rotter, J. "Generalized Expectancies for Internal versus External Control of Reinforcement." Psychological Monographs, 80(1), 1966, pp. 1-28.

[25] Chiu, R. "Ethical judgement, locus of control, and whistleblowing intention: a case study of mainland Chinese MBA students", Managerial Auditing Journal, Vol. 17 Iss: 9, 2002, pp.581 - 587.

[26] Gable, M. and Dangello, F. "Locus of Control, Machiavellianism and Manager Job Performance”, Journal of Psychology, 12, 1998.

[27] Smith, A.; Coates, J. and Deis, D. (1998). "Are Ethical Responses Linked to Locus of Control." Teaching Business Ethics, 2, (3), 1998, pp. 249-260.

[28] Asch, S. (1955). "Opinions and Social Pressure." Scientific American, 1955, pp. 31-35.

[29] Deutsch, M. and Gerard, H. "A Study of Normative and Informational Social Influences Upon Individual Judgment." Abnormal and Social Psychology, 51, 1955, pp. 629-636.

[30] Milgram, S. "Behavioral Study of Obedience." Journal of Abnormal and Social Psychology, 67, 1965, pp. 371-378.

[31] Miller, A. The Obedience Experiments: A Case Study of Controversy in Social Science. New York: Praeger: 1986.

[32] Brief, A.; Dukerich, J. and Doran , L. "Resolving Ethical Dilemmas in Management: Experimental Investigations of Values, accountability and Choice." Journal of Applied Social Psychology, 21, 1981, 380-396.

[33] Darley, J.. and Latane, B. "Bystander Intervention in Emergencies and Diffusion of Responsibility." Journal of Social and Personality Psychology, 8, 1968, pp. 377-383. [34] Latane, B.and Darley, J., "Apathy". American Scientist, 5, 1969, pp. 247-260.

[35] Piliavin, J. and Charng, H. "Altruism: A Review of Recent Theory and Research." Annual Review of Sociology, 16, 1990, pp. 27-65.

[36] Haney, C., Banks, W. C., and Zimbardo, P. G. (1973). "Study of prisoners and guards in a simulated prison." Naval Research Reviews, 9, pp. 1-17. Washington, DC: Office of Naval Research. 
[37] Haaney, C., Banks, W. C., and Zimbardo, P. G. (1973). "Interpersonal dynamics in a simulated prison." International Journal of Criminology and Penology, 1, pp. 69-97.

[38] Reicher, Stephen., \& Haslam, S. Alexander. (2006). "Rethinking the psychology of tyranny: The BBC Prison Study. British Journal of Social Psychology, 45, pp. 1-40.

[39] Zimbardo, P. (2007). The Lucifer Effect. New York: Random House. 